\title{
OPEN Economic impacts of ambient ozone pollution on wood production in Italy
}

\author{
Sandro Sacchelli ${ }^{1}$, Elisa Carrari ${ }^{1,2}$, Elena Paoletti ${ }^{\circledR}$, Alessandro Anav ${ }^{3}$, Yasutomo Hoshika ${ }^{2}$, \\ Pierre Sicard ${ }^{4}$, Augusto Screpanti ${ }^{3}$, Gherardo Chirici ${ }^{1}$, Claudia Cocozza ${ }^{1}$ \& \\ Alessandra De Marco ${ }^{3}$
}

Worldwide, tropospheric ozone $\left(\mathrm{O}_{3}\right)$ is a potential threat to wood production, but our understanding of $\mathrm{O}_{3}$ economic impacts on forests is still limited. To overcome this issue, we developed an approach for integrating $\mathrm{O}_{3}$ risk modelling and economic estimates, by using the Italian forests as a case study. Results suggested a significant impact of $\mathrm{O}_{3}$ expressed in terms of stomatal flux with an hourly threshold of uptake ( $\mathrm{Y}=1 \mathrm{nmol} \mathrm{O}_{3} \mathrm{~m}^{-2}$ leaf area $\mathrm{s}^{-1}$ to represent the detoxification capacity of trees), i.e. POD1. In 2005, the annual POD1 averaged over Italy was $20.4 \mathrm{mmol} \mathrm{m}^{-2}$ and the consequent potential damage ranged from $790.90 \mathrm{M} €$ to $2.85 \mathrm{~B} €$ of capital value (i.e. $255-869 € \mathrm{ha}^{-1}$, on average) depending on the interest rate. The annual damage ranged from 31.6 to $57.1 \mathrm{M} €$ (i.e. $10-17 € \mathrm{ha}^{-1}$ per year, on average). There was also a $1.1 \%$ reduction in the profitable forest areas, i.e. with a positive Forest Expectation Value (FEV), with significant declines of the annual national wood production of firewood (-7.5\%), timber pole (-7.4\%), roundwood $(-5.0 \%)$ and paper mill $(-4.8 \%)$. Results were significantly different in the different Italian regions. We recommend our combined approach for further studies under different economic and phytoclimatic conditions.

Tropospheric ozone $\left(\mathrm{O}_{3}\right)$ pollution affects large areas of the world $\mathrm{d}^{1,2}$. Ozone is strongly phytotoxic and is considered as a serious issue for the health and productivity of forests ${ }^{3}$. Ozone risk assessment may use different $\mathrm{O}_{3}$ metrics $^{4}$ or models ${ }^{1}$. The most common approach is the use of exposure-based metrics e.g. AOT40 i.e. the accumulation of hourly $\mathrm{O}_{3}$ concentrations above $40 \mathrm{ppb}$ for daylight hours during the growing season ${ }^{4}$. However, exposure-based metrics do not incorporate the effects of stomata, that are the only way of $\mathrm{O}_{3}$ entry into the plant ${ }^{5}$. Therefore, a flux-based approach is recommended e.g. by the Convention on Long Range Transboundary Air Pollution of the United Nations ${ }^{6}$ and by the National Emission Ceilings Directive of the European Union ${ }^{7}$, where the stomatal $\mathrm{O}_{3}$ uptake is estimated through models integrating the effects of climatic factors and vegetation characteristics on stomata (e.g. the DO3SE model ${ }^{8}$ ). Such flux metric is called Phytotoxic Ozone Dose, defined as the amount of $\mathrm{O}_{3}$ absorbed into the leaves or needles through stomata over the growing season, and above a threshold Y of uptake (PODY).

Among the many ecosystem services provided by forests, only wood production losses have been estimated so far to assess the economic impact of $\mathrm{O}_{3}$ pollution on forests ${ }^{-11}$, because experimental dose-response relationships are available for estimating biomass losses ${ }^{12-14}$. Feng et al. ${ }^{11}$ used the AOT40-response relationship and reported that current levels of $\mathrm{O}_{3}$ across China may cause economic losses of forest production equivalent to 52.2 billion US\$ in 2015. Karlsson et al. ${ }^{9}$ similarly applied the AOT40-based approach to Swedish forests and simulated that the potential annual economic loss of forest production due to $\mathrm{O}_{3}$ was 56.0 million $€$ over the time period 1993-2003. Felzer et al. ${ }^{10}$ predicted the $\mathrm{O}_{3}$ effects on carbon sequestration in crops, pastures and forests at global scale by using the empirical function of AOT40 for gross primary production (GPP) and found that reduced $\mathrm{CO}_{2}$ uptake due to $\mathrm{O}_{3}$ exposure would increase the macroeconomic consumption cost of the greenhouse gas policy by 4.5 trillion US\$ in 2100 . Wood is central in a sustainable bioeconomy, e.g. forestry and extended wood-based value chains employed 4.5 million people in the European Union in $2018^{15}$.

Given the limited knowledge on the economic value of $\mathrm{O}_{3}$-induced wood production losses, in particular according to a flux-based approach, the aim of this study was to develop a combined modelling approach for realistic estimates of the economic impacts of POD1-based wood losses, by using Italy as a case study. Italy is a well-known hot-spot of $\mathrm{O}_{3}$ pollution, given its central position in the Mediterranean basin in Southern

${ }^{1}$ Department of Agriculture, Food, Environment and Forestry, P.le delle Cascine 18/via San Bonaventura 13, Florence, Italy. ${ }^{2}$ IRET-CNR, Via Madonna del Piano 10, Sesto Fiorentino, Italy. ${ }^{3}$ ENEA, Casaccia, Rome, Italy. ${ }^{4}$ ARGANS, 260 route du Pin Montard, Sophia-Antipolis, France. ${ }^{\boxplus}$ email: elena.paoletti@cnr.it 


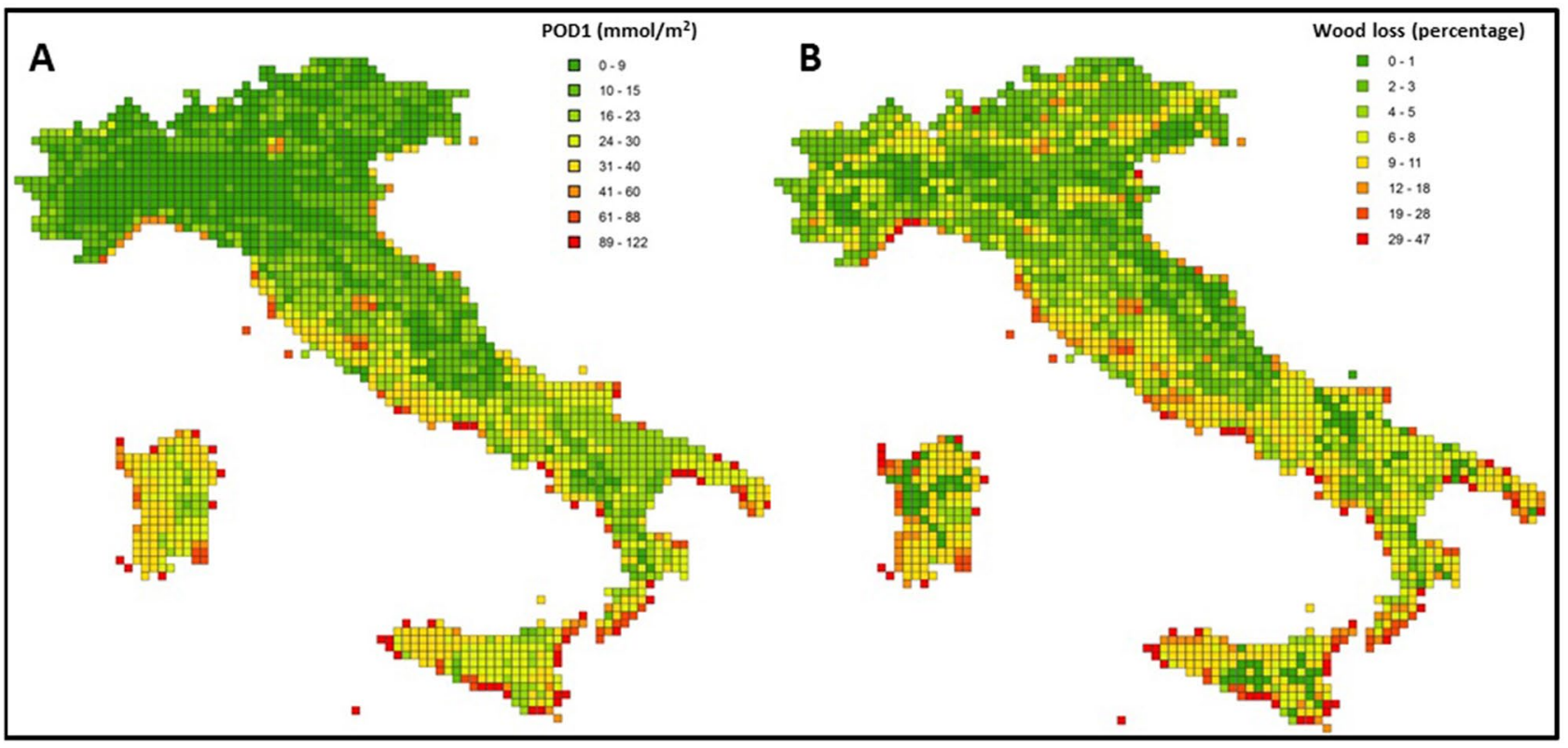

Figure 1. (A) Stomatal ozone uptake over a threshold of $1 \mathrm{nmol} \mathrm{O}_{3} \mathrm{~m}^{-2} \mathrm{~s}^{-1}$ (POD1) and (B) wood loss (\%) in the POD1 scenario relative to the no ozone damage scenario (WO) estimated over a $12 \times 12 \mathrm{~km}$ grid along Italy in the year 2005. Maps were created by QGIS (https://www.qgis.org/it/site/).

Europe where climate and economic conditions promote $\mathrm{O}_{3}$ pollution ${ }^{16.17}$. In 2001, the Italian wood sectors employed 413,872 workers in 87,546 companies with a total turnover of about $\$ 35$ billion, with the furniture sector accounting for $\$ 20.8$ billion $^{18}$. We expect that this approach and results stimulate further studies by using a harmonized methodology for a better economic understanding of the global impacts of $\mathrm{O}_{3}$ pollution on forests and the forestry sector.

\section{Results}

POD1 values across Italy ranged between 0.3 and $100 \mathrm{mmol} \mathrm{m}^{-2}$, with a spatial distribution showing lower values in the Alps mountains in the North and higher values over the peninsula and the islands where the climate is typically Mediterranean (Fig. 1A). The average value of POD1 was $20.4 \mathrm{mmol} \mathrm{m}^{-2}$ ranging from $8.0 \mathrm{mmol} \mathrm{m}^{-2}$ in Piedmont to $41.4 \mathrm{mmol} \mathrm{m}^{-2}$ in Sardinia (Fig. 1S).

Results suggested a significant impact of $\mathrm{O}_{3}$ (POD1) on Italian wood losses, that reached almost half of the expected wood production in the no ozone scenario (WO) at individual grid points (Fig. 1B) as well as a significant influence of the interest rate $(r)$ on economic trend. Indeed, the total capital value of Italian forests in the WO scenario (no ozone) ranged from 8.0 to $29.5 \mathrm{~B} €$ and from 2578 to $8987 €$ ha $^{-1}$ with $2-4 \%$ of interest rate (Table 1). The POD1 scenario caused a total potential damage from $790.9 \mathrm{M} €$ to $2.85 \mathrm{~B} €$ of capital value (255-869 $€ \mathrm{ha}^{-1}$, on average). The annual damage ranged from 31.6 to $57.1 \mathrm{M} €\left(10-17 € \mathrm{ha}^{-1} \mathrm{year}^{-1}\right.$, on average). The relative economic impact from WO to POD1 scenario was about $10 \%$ (total damage) and about $9 \%$ (average damage) for all interest rates. In addition, the total forest area with FEV $>0$ decreased by around $1.1 \%$ from WO to POD1 (Table 2). The reduction ranged from 35,358 ha with $r=3 \%$ to 37,774 ha with $r=4 \%(1.1 \%$ and $1.2 \%$ of total forest area, respectively).

The $\mathrm{O}_{3}$ impact on potential national wood production is reported in Table 3. According to the forest characteristics of Italy (widespread broadleaved stands, coppice management, private properties, etc.), the most represented wood assortment was firewood (from 5,449,258 to 5,603,228 $\mathrm{m}^{3}$ year $^{-1}$ in WO scenario), followed by timber pole (from 818,390 to $824,274 \mathrm{~m}^{3}$ year $^{-1}$ ), roundwood (from 587,011 to $672,446 \mathrm{~m}^{3} \mathrm{year}^{-1}$ ) and paper mill (from 288,511 to $365,174 \mathrm{~m}^{3}$ year $^{-1}$ ). Firewood and timber pole were strongly affected by moving from WO to POD1 scenario (on average the reduction was $7.5 \%$ and $7.4 \%$, respectively). The decrease of roundwood and paper mill (on average $5.0 \%$ and $4.8 \%$, respectively) was lower than that for timber pole and firewood.

The Italian administrative regions were affected by $\mathrm{O}_{3}$ in different ways (Table 4). Total damage was affected more by the forest surface than by the average POD1 value of the region, i.e. was higher in regions with higher forest areas (from 1.03 M€ in the small Aosta Valley to 191.4 M€ in the big and highly forested Tuscany, equivalent to 0.03 and $5.70 \mathrm{M} €$ year $^{-1}$, respectively). The average capital value showed higher impacts in Liguria (1229 $\left.€ \mathrm{ha}^{-1}\right)$, Campania $\left(628 € \mathrm{ha}^{-1}\right)$, Calabria $\left(568 € \mathrm{ha}^{-1}\right)$ and Lazio $\left(527 € \mathrm{ha}^{-1}\right)$ i.e. $37,19,17$ and $16 € \mathrm{ha}^{-1} \mathrm{year}^{-1}$, respectively. The reduction of profitable forest area, i.e. with FEV $>0$, was strongly affected by the POD1 level, and was higher in Sardinia ( $-10,752$ ha of forest surface area, $41.4 \mathrm{mmol} \mathrm{m}^{-2}$ POD1), followed by Calabria ( -5811 ha, $33.2 \mathrm{mmol} \mathrm{m}^{-2}$ ), Sicily $\left(-3362 \mathrm{ha}, 40.9 \mathrm{mmol} \mathrm{m}^{-2}\right)$, and then by highly forested regions with relatively lower POD1 levels such as Tuscany $\left(-2432 \mathrm{ha}, 20.6 \mathrm{mmol} \mathrm{m}^{-2}\right)$ and Trentino-South Tyrol $\left(-2319 \mathrm{ha}, 9.2 \mathrm{mmol} \mathrm{m}^{-2}\right)$. In relative terms, the decrease of profitable forests still occurred in Sardinia (6.2\%), Sicily (3.1\%) and Calabria (2.5\%) but also in regions with a limited forest coverage but high POD1 level (e.g. 2.9\% of reduction in Apulia, $32.2 \mathrm{mmol} \mathrm{m}^{-2}$ ). 


\begin{tabular}{|c|c|c|c|c|}
\hline Scenario-FEV & Economic metrics & $\mathbf{r}=\mathbf{2} \%$ & $\mathbf{r}=3 \%$ & $\mathrm{r}=4 \%$ \\
\hline \multirow{4}{*}{ Scenario WO } & Total $(\times 1000 €)$ & $29,515,620$ & $13,698,530$ & $7,988,405$ \\
\hline & Average $\left(€ \mathrm{ha}^{-1}\right)$ & 8987 & 4293 & 2578 \\
\hline & Total annualized value $\left(€\right.$ year $\left.^{-1}\right)$ & $590,312,400$ & $410,955,900$ & $319,536,200$ \\
\hline & Average annualized value $\left(€ \mathrm{ha}^{-1}\right.$ year $\left.^{-1}\right)$ & 180 & 129 & 103 \\
\hline \multirow{4}{*}{ Scenario POD1 } & Total $(\times 1000 €)$ & $26,662,800$ & $12,356,890$ & $7,197,459$ \\
\hline & Average $\left(€ \mathrm{ha}^{-1}\right)$ & 8210 & 3916 & 2352 \\
\hline & Total annualized value $\left(€\right.$ year $\left.^{-1}\right)$ & $533,256,000$ & $370,706,700$ & $287,898,360$ \\
\hline & Average annualized value $\left(€\right.$ ha $^{-1}$ year $\left.^{-1}\right)$ & 164 & 117 & 94 \\
\hline \multirow{4}{*}{ FEV decrease from WO to POD1 } & Total $(\times 1000 €)$ & $2,852,820$ & $1,341,640$ & 790,946 \\
\hline & Average $\left(€ \mathrm{ha}^{-1}\right)$ & 869 & 420 & 255 \\
\hline & Total annualized value $\left(€\right.$ year $\left.^{-1}\right)$ & $57,056,400$ & $40,249,200$ & $31,637,840$ \\
\hline & Average annualized value $\left(€ \mathrm{ha}^{-1}\right.$ year $\left.^{-1}\right)$ & 17 & 13 & 10 \\
\hline \multirow{4}{*}{ FEV decrease from WO to POD1 } & Total $(\%)$ & $9.7 \%$ & $9.8 \%$ & $9.9 \%$ \\
\hline & Average (\%) & $8.6 \%$ & $8.8 \%$ & $8.8 \%$ \\
\hline & Total annualized value (\%) & $9.7 \%$ & $9.8 \%$ & $9.9 \%$ \\
\hline & Average annualized value (\%) & $8.6 \%$ & $8.8 \%$ & $8.8 \%$ \\
\hline
\end{tabular}

Table 1. Forest expectation value (FEV) under no ozone damage scenario (WO) and with a forest-type specific reduction in the annual forest increment as estimated on the basis of the phytotoxic ozone dose (POD1). Results are for the Italian forests in 2005, with different interest rates $r$.

\begin{tabular}{|l|l|l|l|}
\hline Total forest area with FEV $>\mathbf{0}$ & $\mathbf{r}=\mathbf{2 \%}$ & $\mathbf{r}=\mathbf{3} \%$ & $\mathbf{r}=\mathbf{4 \%}$ \\
\hline Scenario WO (ha) & $3,284,092$ & $3,190,924$ & $3,098,154$ \\
\hline Scenario POD1 (ha) & $3,247,741$ & $3,155,566$ & $3,060,380$ \\
\hline FEV decrease from WO to POD1 (ha) & 36,351 & 35,358 & 37,774 \\
\hline FEV decrease from WO to POD1 (\%) & $1.1 \%$ & $1.1 \%$ & $1.2 \%$ \\
\hline
\end{tabular}

Table 2. Total forest area (ha) with FEV $>0$ and its decrease under no ozone damage scenario (WO) and phytotoxic ozone dose (POD1) scenario. Results are for the Italian forests in 2005, with different interest rates $\mathrm{r}$.

\begin{tabular}{|l|l|l|l|l|}
\hline Scenario & Wood assortment & $\mathbf{r}=\mathbf{2 \%}$ & $\mathbf{r}=\mathbf{3 \%}$ & $\mathbf{r}=\mathbf{4 \%}$ \\
\hline \multirow{4}{*}{ Scenario WO $\left(\mathrm{m}^{3}\right.$ year $\left.^{-1}\right)$} & Roundwood & 672,446 & 633,599 & 587,011 \\
\cline { 2 - 5 } & Timber pole & 824,274 & 821,480 & 818,390 \\
\cline { 2 - 5 } & Paper mill & 365,174 & 328,267 & 288,511 \\
\cline { 2 - 5 } & Firewood & $5,603,228$ & $5,525,739$ & $5,449,258$ \\
\hline \multirow{5}{*}{ Scenario POD1 $\left(\mathrm{m}^{3}\right.$ year $\left.^{-1}\right)$} & Roundwood & 638,358 & 601,818 & 557,872 \\
\cline { 2 - 5 } & Timber pole & 762,918 & 760,319 & 757,445 \\
\cline { 2 - 5 } & Paper mill & 347,307 & 312,624 & 275,093 \\
\cline { 2 - 5 } & Firewood & $5,181,820$ & $5,111,302$ & $5,041,343$ \\
\hline \multirow{5}{*}{ Loss from WO to POD1 $\left(\mathrm{m}^{3} \mathrm{year}^{-1}\right)$} & Roundwood & 34,088 & 31,781 & 29,139 \\
\cline { 2 - 5 } & Timber pole & 61,356 & 61,161 & 60,945 \\
\cline { 2 - 5 } & Paper mill & 17,867 & 15,643 & 13,418 \\
\cline { 2 - 5 } & Firewood & 421,408 & 414,437 & 407,915 \\
\cline { 2 - 5 } & Total & 534,719 & 523,022 & 511,417 \\
\hline \multirow{5}{*}{ Loss from WO to POD1 $(\%)$} & Roundwood & $5.1 \%$ & $5.0 \%$ & $5.0 \%$ \\
\cline { 2 - 5 } & Timber pole & $7.4 \%$ & $7.4 \%$ & $7.4 \%$ \\
\cline { 2 - 5 } & Paper mill & $4.9 \%$ & $4.8 \%$ & $4.7 \%$ \\
\hline & Firewood & $7.5 \%$ & $7.5 \%$ & $7.5 \%$ \\
\hline & Average & $6.2 \%$ & $6.2 \%$ & $6.1 \%$ \\
\hline
\end{tabular}

Table 3. Timber production under no ozone damage scenario (WO) and phytotoxic ozone dose (POD1) scenario in Italy in 2005 and potential losses, with different interest rates $\mathrm{r}$. 


\begin{tabular}{|c|c|c|c|c|c|}
\hline $\begin{array}{l}\text { Administrative region } \\
\text { (from North to South) }\end{array}$ & $\begin{array}{l}\text { Forest area (ha) and forest } \\
\text { coverage (\%) }\end{array}$ & $\begin{array}{l}\text { FEV decrease from WO to } \\
\text { POD1 }(€)\end{array}$ & $\begin{array}{l}\text { FEV decrease from WO to } \\
\text { POD1 }\left(€ \mathrm{ha}^{-1}\right)\end{array}$ & $\begin{array}{l}\text { Decrease of forest surface } \\
\text { with FEV }>0 \text { from WO to } \\
\text { POD1 (ha) }\end{array}$ & $\begin{array}{l}\text { Decrease of forest surface } \\
\text { with FEV >0 from WO to } \\
\text { POD1 (\%) }\end{array}$ \\
\hline Piedmont & $940,116(37 \%)$ & $111,584,377$ & 421 & 2122 & 0.8 \\
\hline Aosta Valley & $105,928(32 \%)$ & $1,033,377$ & 120 & 197 & 2.3 \\
\hline Lombardy & $665,703(28 \%)$ & $62,116,668$ & 438 & 954 & 0.7 \\
\hline Trentino-South Tyrol & $779,705(57 \%)$ & $15,603,706$ & 97 & 2319 & 1.4 \\
\hline Veneto & $446,856(24 \%)$ & $50,099,297$ & 415 & 565 & 0.5 \\
\hline Friuli-Venezia Giulia & $357,224(45 \%)$ & $35,020,870$ & 409 & 1049 & 1.2 \\
\hline Liguria & $375,134(69 \%)$ & $163,607,975$ & 1229 & 435 & 0.3 \\
\hline Emilia Romagna & $608,818(28 \%)$ & $73,212,285$ & 294 & 644 & 0.3 \\
\hline Tuscany & $1,151,539(50 \%)$ & $191,470,424$ & 338 & 2432 & 0.4 \\
\hline Umbria & $390,255(46 \%)$ & $63,015,131$ & 462 & 256 & 0.2 \\
\hline Marche & $308,076(32 \%)$ & $24,256,891$ & 368 & 376 & 0.6 \\
\hline Lazio & $605,859(35 \%)$ & $84,261,787$ & 527 & 422 & 0.3 \\
\hline Abruzzo & $438,590(41 \%)$ & $26,627,345$ & 234 & 325 & 0.3 \\
\hline Molise & $148,641(33 \%)$ & $33,567,015$ & 438 & 285 & 0.4 \\
\hline Campania & $445,274(33 \%)$ & $121,124,452$ & 628 & 831 & 0.4 \\
\hline Apulia & 179,094 (9\%) & $22,399,791$ & 456 & 1407 & 2.9 \\
\hline Basilicata & $356,426(36 \%)$ & $48,243,555$ & 311 & 814 & 0.5 \\
\hline Calabria & $612,931(41 \%)$ & $132,897,988$ & 568 & 5811 & 2.5 \\
\hline Sicily & $338,171(13 \%)$ & $58,191,732$ & 543 & 3362 & 3.1 \\
\hline Sardinia & $1,213,250(50 \%)$ & $23,299,207$ & 134 & 10,752 & 6.2 \\
\hline
\end{tabular}

Table 4. Reduction of forest expectation value (FEV) and forest area from the WO to the POD1 scenario. Results are for Italian regions in 2005, with interest rate $r=3 \%$

\section{Discussion}

We merged an open-source add-on GIS software tool for estimating the economic value of forests ${ }^{19}$ with a classic $\mathrm{O}_{3}$ risk assessment approach ${ }^{6,20}$, and used forest inventory and WRF-CHIMERE outputs to spatially estimate the $\mathrm{O}_{3}$-induced wood losses in the year 2005. We used the accumulated stomatal $\mathrm{O}_{3}$ uptake (POD1) as a metric of $\mathrm{O}_{3}$ damage because it is considered as a better index than only $\mathrm{O}_{3}$ concentrations in the air ${ }^{21}$. However, estimating POD1 at fine scale is challenging as it requires hourly inputs ${ }^{22}$. For the first time, an economic valuation of wood losses was based on POD1 at high spatial horizontal resolution $\left(12 \mathrm{~km}^{2}\right)$.

Italy is known to be subject to elevated $\mathrm{O}_{3}$ pollution ${ }^{16}$ and is thus an ideal case study for applying this combined approach. In fact, the average POD1 value of Italy was $20.4 \mathrm{mmol} \mathrm{m}^{-2}$ with spikes up to $100 \mathrm{mmol} \mathrm{m}^{-2}$. Such values are higher than values estimated at individual forest stands in central and Northern Europe (Tatra mountains ${ }^{23}, 14-16 \mathrm{mmol} \mathrm{m}^{-2}$; Southern Sweden ${ }^{24}, \sim 18 \mathrm{mmol} \mathrm{m}^{-2}$ ) and similar to values simulated for EastAsian forests (continental and (sub)tropical forests ${ }^{20}, 20-105 \mathrm{mmol} \mathrm{m}^{-2}$ ). Also East Asia is known as a hot-spot of $\mathrm{O}_{3}$ pollution ${ }^{25}$. The spatial distribution of POD1 along the Italian peninsula showed lower values in the Alpine forests in the North (on average $12 \mathrm{mmol} \mathrm{m}^{-2}$ ) and higher values in the typical Mediterranean climate of the South (on average $\left.23 \mathrm{mmol} \mathrm{m}^{-2}\right)$ and the islands $\left(\sim 41 \mathrm{mmol} \mathrm{m}^{-2}\right)$. These values and the North-to-South increase are similar to what observed for the entire Europe ${ }^{26}$, as the warmer climate in the South stimulates $\mathrm{O}_{3}$ formation $^{27}$. These POD1 values are well above the critical levels of 4 and $8 \mathrm{mmol} \mathrm{m}^{-2}$ identified by ${ }^{28}$ for the protection of deciduous broadleaves (birch and beech) and conifers (Norway spruce), respectively, stressing that most of Italian forests are exposed to severe $\mathrm{O}_{3}$ risks.

Modelling $\mathrm{O}_{3}$ impact on Italian forests showed a marked decrease of their economic value. According to applied interest rate, annual damage ranged from 31.6 to $57.0 \mathrm{M} €$ per year with a loss of capital value of about $10 \%$. Among the few previous papers on the economic impact of $\mathrm{O}_{3}$ on forests, none used a methodology comparable with the present research [9-11]. However, Karlsson et al. ${ }^{9}$ indicated similar results as the potential annual economic loss for Sweden due to negative impacts of $\mathrm{O}_{3}$ on forest production was of the order of $56 \mathrm{M} €$ that is about $2.4 € \mathrm{ha}^{-1}$ year $^{-1}$, while in Italy it ranged from 3.02 to $5.46 € \mathrm{ha}^{-1}$ year $^{-1}$ (r: $\left.2-4 \%\right)$. The variability of potential economic impact among Italian administrative regions reflected the strong dissimilarity of geomorphological, logistic, vegetational as well as socio-economic conditions of Italian forests ${ }^{29}$. We innovatively defined the economic damage by $\mathrm{O}_{3}$ also in terms of reduction of forest area with positive FEV. This reduction in the POD1 scenario was about 1.1-1.2\% of the total forest area. This loss of stands with economic profitability may make active forest management no longer meaningful, which would result in an indirect negative effect due to the worsening of other ecosystem services ${ }^{30}$. As an example, hydrogeological problems or fire risk-which are relevant issues for the Italian territory-can increase due to a decline of silvicultural practices ${ }^{31}$. In general, trade-offs among provisioning and other forest benefits (regulating, supporting and cultural services ${ }^{32}$ ) can happen and they may be measured not only in biophysical but also in economic terms ${ }^{33}$. A POD1-induced loss from about 535,000 to $511,000 \mathrm{~m}^{3}$ year $^{-1}$ of wood assortments was also estimated. Firewood was the most impacted product (from 421,408 to $407,915 \mathrm{~m}^{3}$ year $^{-1}$ of reduction) but the structure of Italian forest chain and the high 
added value for the other timber outputs (e.g., roundwood) suggested a potential negative cascade effect on the whole forest chain and on ancillary activities.

\section{Conclusions}

This work is one of the first fine-scale combined models to quantify the economic impacts of $\mathrm{O}_{3}$ at national level. Results highlighted that the reduction of forest area with active management is limited to the most severely $\mathrm{O}_{3}$ polluted areas, even though significant negative effects on timber production occur all across Italy. Consequences on other forest ecosystem services and socio-economic deterioration of the forest chain, such as occupational consequences and cascade effect on satellite activities, should be evaluated. This aspect indicates that the elevated economic impact (loss of capital and annual values of forest) here presented, is still an underestimation of the total losses.

The open source software facilitates replicability as well as sensitivity analysis. Spatial analysis can take into account local peculiarities, thus helping to improve models and results, and finally resulting into guidelines to cope with the potential negative impacts of $\mathrm{O}_{3}$ pollution on forests and the forestry sector. This GIS-based application is thus a valuable tool to quantify and localize potential negative impacts. Ozone damages can interfere with the vitality of species of plant communities, as well as that of the animals, fungi, bacteria and insects that live in close association with plants or in nearby soils ${ }^{34}$. Changes induced by $\mathrm{O}_{3}$ impact on many ecological processes, affecting ecosystem services, flows, goods and values. Further activities in the definition of ecosystem-scale models suitable to extrapolate effects of $\mathrm{O}_{3}$ on productivity of trees and entire ecosystems might be addressed to economically quantify also the loss of other ecosystem services such as biodiversity, resource allocation and/ or seed production.

\section{Methodology}

Study area and forest data. Data of biomass availability were obtained from the pan-European map of forest biomass increment ${ }^{35}$. The map was validated using information from the most recent and free georeferenced Italian National Forest Inventory, i.e. for the year $2005^{36}$. In Italy, the total forested area was 10,467,533 ha in 2005. There was a certain variability of forest cover (in percentage) as well as vegetation, geomorphologic, logistics and socio-economic characteristics among regions (NUTS-2 level). Private forests accounted for 63.5\% of the total, and coppice was the prevalent forest management (54.0\%). The most common forest typology was broadleaved species ( $83.6 \%$ of total area), mainly oaks (23.9\% of broadleaved, mostly Quercus robur and Q. cerris), as well as Fagus sylvatica (11.8\%) and Castanea sativa (9\%). Among the conifers (16.4\% of total area), Picea abies prevailed (34.2\%), in particular in the Alpine forests ${ }^{36}$.

Modelling ozone pollution. Hourly $\mathrm{O}_{3}$ concentrations and hourly meteorological data needed to calculate POD1 (i.e. solar radiation, air temperature, relative humidity, soil water content, wind speed) were simulated over the domain at $12 \times 12 \mathrm{~km}$ of horizontal resolution by the WRF-CHIMERE modelling system, as described $i^{26}$. The $\mathrm{O}_{3}$ concentrations at 20-25 m above ground level (top of the canopy) provided by CHIMERE were used to calculate PODY. For PODY, a threshold Y of $1 \mathrm{nmol} \mathrm{m}^{-2} \mathrm{~s}^{-1}$ per leaf area as recommended by ${ }^{6}$ for forest protection was applied, and computed as in $^{6,37}$ :

$$
\operatorname{POD} 1(t)=\int_{S G S}^{E G S} \max \left(\frac{R c}{R b+R c} \times g_{\text {sto }} \times\left[\mathrm{O}_{3}\right]-1,0\right) d t
$$

where $\left[\mathrm{O}_{3}\right]$ is hourly $\mathrm{O}_{3}$ concentrations (ppb), $d t$ is time step ( $1 \mathrm{~h}$ ), SGS and EGS are the start and end date of the growing season computed as described in ${ }^{38}, R_{b}$ is the quasi-laminar resistance $\left(\mathrm{s} \mathrm{m}^{-1}\right), \mathrm{R}_{\mathrm{c}}$ is the leaf surface resistance $\left(\mathrm{s} \mathrm{m}^{-1}\right)$, and $\mathrm{g}_{\text {sto }}$ is the hourly value of stomatal conductance to $\mathrm{O}_{3}\left(\mathrm{mmol} \mathrm{O}_{3} \mathrm{~m}^{-2}\right.$ PLA s${ }^{-1}$, where PLA is the Projected Leaf Area) computed as following:

$$
g_{\text {sto }}=g_{\text {max }} \times f_{\text {phen }} \times f_{\text {light }} \times \max \left\{\left\{f_{\text {min }},\left(f_{\text {temp }} \times f_{V P D} \times f_{S W C}\right)\right\}\right.
$$

where $\mathrm{g}_{\max }$ is the maximum stomatal conductance to $\mathrm{O}_{3}$ of a plant species expressed on a total leaf surface area $\left(\mathrm{mmol} \mathrm{O}_{3} \mathrm{~m}^{-2} \mathrm{PLA} \mathrm{s}^{-1}\right)$. The maximum stomatal conductance $\left(\mathrm{g}_{\max }\right)$ is experimentally obtained as average above the $90^{\text {th }}$ or $98^{\text {th }}$ percentile of $g_{\text {sto }}$ measurements under optimum environmental conditions for stomatal opening $^{6,14}$. The functions $f_{\text {phen }}, f_{\text {light }}, f_{\text {temp }}, f_{\mathrm{VPD}}$, and $f_{\mathrm{SWC}}$ are the variation in $g_{\max }$ with leaf age, photosynthetically flux density at the leaf surface (PPFD, $\mu$ mol photons $\left.\mathrm{m}^{-2} \mathrm{~s}^{-1}\right)$, surface air temperature $\left(\mathrm{T},{ }^{\circ} \mathrm{C}\right)$, vapour pressure deficit (VPD, $\mathrm{kPa}$ ), and volumetric soil water content (SWC, $\mathrm{m}^{3} \mathrm{~m}^{-3}$ ), respectively. The function $f_{\min }$ is the minimum stomatal conductance. These species-specific functions vary between 0 and 1 , and are expressed as:

$$
\begin{gathered}
f_{\text {light }}=1-e^{\left(- \text {light }_{a} \times P P F D\right)} \\
f_{\text {temp }}=\left(\frac{T-T_{\min }}{T_{\text {opt }}-T_{\min }}\right) *\left[\left(\frac{T_{\max }-T}{T_{\max }-T_{\text {opt }}}\right)^{\left(\frac{T_{\max }-T_{\text {opt }}}{T_{\text {opt }}-T_{\min }}\right)}\right] \\
f_{V P D}=\min \left\{1, \max \left[f_{\min },\left(\frac{\left(1-f_{\min }\right) *\left(V P D_{\min }-V P D\right)}{V P D_{\min }-V P D_{\max }}\right)+f_{\min }\right]\right\}
\end{gathered}
$$




\begin{tabular}{|l|l|l|l|l|l|l|}
\hline Biogeographic region & \multicolumn{2}{l}{ Alpine } & \multicolumn{2}{l|}{ Continental } & \multicolumn{2}{l|}{ Mediterranean } \\
\hline Forest type & Evergreen & Deciduous & Evergreen & Deciduous & Evergreen & Deciduous \\
\hline $\mathrm{g}_{\text {max }}\left(\mathrm{mmol} \mathrm{m}_{3} \mathrm{~m}^{-2} \mathrm{PLA} \mathrm{s}^{-1}\right)$ & 125 & 240 & 130 & 155 & 195 & 265 \\
\hline fmin $(f r a c t i o n$ of g gax & 0.10 & 0.10 & 0.16 & 0.13 & 0.02 & 0.13 \\
\hline light_a $(\mathrm{dl})$ & 0.0060 & 0.0042 & 0.0100 & 0.0060 & 0.0120 & 0.0060 \\
\hline $\mathrm{T}_{\min }\left({ }^{\circ} \mathrm{C}\right)$ & 0 & 5 & 0 & 5 & 1 & 0 \\
\hline $\mathrm{T}_{\text {opt }}\left({ }^{\circ} \mathrm{C}\right)$ & 20 & 20 & 14 & 16 & 23 & 22 \\
\hline $\mathrm{T}_{\text {max }}\left({ }^{\circ} \mathrm{C}\right)$ & 200 & 200 & 35 & 33 & 39 & 35 \\
\hline $\mathrm{VPD}_{\text {max }}(\mathrm{kPa})$ & 0.8 & 0.5 & 0.5 & 1.0 & 2.2 & 1.1 \\
\hline $\mathrm{VPD}_{\text {min }}(\mathrm{kPa})$ & 2.8 & 2.7 & 3.0 & 3.1 & 4.0 & 3.1 \\
\hline
\end{tabular}

Table 5. Forest-type parameterization of DO3SE model according to ${ }^{6} \cdot \mathrm{g}_{\max }$, maximum stomatal conductance; $f_{\min }$ minimum stomatal conductance; $f_{\text {light_a }}$ parameter determining the shape of the hyperbolic relationship of stomatal response to light (dimensionless); $\mathrm{T}_{\max }, \mathrm{T}_{\text {opt }}$ and $\mathrm{T}_{\min }$ are maximum, optimal and minimum temperature for calculating the function $f_{\text {temp }}$ that expresses the variation of $g_{\max }$ with temperature; $\mathrm{VPD}_{\min }$ and $\mathrm{VPD}_{\max }$ are the vapor pressure deficit for attaining minimum and full stomatal aperture calculating the function $f_{\mathrm{VPD}}$ that expresses the variation of $g_{\max }$ with vapor pressure deficit. The parameters for the soil water content $\left(f_{\text {swC }}\right)$ and phenological functions $\left(f_{\text {phen }}\right)$ are obtained by the WRF model and vary with the latitude.

\begin{tabular}{|l|l|}
\hline Forest type & Dose-response function \\
\hline Alpine deciduous & $\mathrm{L}=100.2-\left(0.93^{\star P O D} 1\right)$ \\
\hline Alpine evergreen & $\mathrm{L}=99.8-\left(0.22^{\star P O D} 1\right)$ \\
\hline Continental deciduous & $\mathrm{L}=100.2-\left(0.93^{\star} \mathrm{POD} 1\right)$ \\
\hline Continental evergreen & $\mathrm{L}=99.8-\left(0.22^{\star P O D} 1\right)$ \\
\hline Mediterranean deciduous & $\mathrm{L}=100.3-\left(0.32^{\star P O D} 1\right)$ \\
\hline Mediterranean evergreen & $\mathrm{L}=99.8-\left(0.09^{\star} \mathrm{POD} 1\right)$ \\
\hline
\end{tabular}

Table 6. Forest-type dose-response functions to estimate total biomass losses (L) based on the cumulated stomatal ozone flux above a threshold of $1 \mathrm{mmol} \mathrm{m}^{-2}$ (POD1) according to ${ }^{6}$.

$$
f_{S W C}=\min \left[1, \max \left(f_{\min }, \frac{S W C-W P}{F C-W P}\right)\right]
$$

where light $\mathrm{a}_{\mathrm{a}}$ is an adimensional constant; PPFD is hourly photosynthetic photon flux density estimated through the solar radiation; $\mathrm{T}_{\mathrm{opt}}, \mathrm{T}_{\min }$, and $\mathrm{T}_{\max }$ represent the optimum, minimum, and maximum temperature for $\mathrm{g}_{\text {sto, }}$, respectively; $\mathrm{VPD}_{\min }$ and $\mathrm{VPD}_{\max }$ are minimum and maximum $\mathrm{VPD}$ for $\mathrm{g}_{\text {sto }}$; and $\mathrm{WP}$ and $\mathrm{FC}$ are the soil water content (SWC) at wilting point and field capacity, respectively ${ }^{6}$ WP and FC are constant and depend on the soil type obtained from a module included into the WRF-CHIMERE model. We assumed that $f_{\text {phen }}$ was 1 throughout the growing season (0 otherwise).

Six types of parameterization were used based on the six dominant forest types identified by land cover and climate over Italy, i.e. Alpine (for which the Boreal parameterizations in ${ }^{6}$ was used), Continental and Mediterranean with either Deciduous or Evergreen species (Table 5). After calculation of POD1, the dose-response functions specific per each forest type were applied in each $12 \times 12 \mathrm{~km}$ grid point according to Table 6 .

Modelling ozone-induced wood losses. The economic value of Italian forests was quantified through a spatial-based analysis centered on the r.green.biomassfor model ${ }^{39}$. The tool is available as open-source add-on in GRASS Geographic Information System (GIS) software (https://grass.osgeo.org/grass78/manuals/addons/r. green.biomassfor.html). The model allows a quantification of wood assortments as well as their economic value by a multistep procedure. First, the so-called "technical availability" of material is quantified considering logistic (distance from forest/main roads or landing site) and geomorphological conditions (slope and terrain roughness). The combination of the above variables allows defining forest production process in terms of organization of cutting, processing and extraction. The second step introduces the economic parameters to calculate revenues from sell of assortments and full costs. Potentially available material is finally quantified on forest surfaces with economic profitability of production process. In the original version of the model, profitability was expressed as positive stumpage value (difference between revenues and costs of final harvesting / thinning). Here-in order to evaluate a long-term impact - the positive forest expectation value (FEV) (capital value of bare land plus timber at year $y$ ) was considered as index of economic profitability. FEV corresponds to the present value of cashflows arising from both the land and the tree, in perpetuity ${ }^{40}$. Input data to run r.green.biomassfor in Italy were derived from ${ }^{19}$ and are provided in Tables S1 and S2. The complete procedure was developed on raster basis with a resolution of 1 ha (squared pixel of $100 \times 100 \mathrm{~m}$ ). Wood losses due to $\mathrm{O}_{3}$ were computed taking into account the reduction of forest increment. In the present work, two scenarios were developed to quantify FEV and-as 
a consequence-forest surface with positive economic value and wood production: (i) a hypothetical scenario without $\mathrm{O}_{3}$ impact (WO) and (ii) a scenario based on POD1 limiting biomass production. The software r.green. biomassfor was then ran for both scenarios and results were reported at national and administrative (regions) level. FEV for each scenario $s$ (FEVs) was calculated as in ${ }^{41}$ based on the "future revenues" approach:

$$
F E V_{s}=\frac{S V_{s}+\sum_{m} T_{s} \cdot q^{t_{s}-m_{s}}+\left(v_{s}-e_{s}\right) \cdot\left(\frac{q^{t_{s}-n_{s}}-1}{r}\right)+L E V_{s}}{q^{t_{s}-n_{s}}}
$$

where $S V$ is stumpage value of final harvesting, $T$ is stumpage value of intermediate thinning, $t$ is rotation period, $m$ is year of thinning, $n$ is age of the forest, $v$ and $e$ are yearly income and cost, respectively, $q=1+r$ with $r$ interest rate, $L E V$ is the land expectation value (bare soil) calculated as $i^{42}$ :

$$
L E V_{s}=\frac{S V_{s}+\sum_{m} T_{s} \cdot q^{t_{s}-m_{s}}}{q^{t_{s}}-1}+\frac{v_{s}-e_{s}}{r}
$$

FEVs were calculated at national and region level for both total (€) (Eq. 9) and average (€/ha) (Eq. 10) values. As POD1-based damage is accumulated over the growing season, total and average FEVs were annualized (aFEV) as expressed in Eq. (11) and Eq. (12), respectively.

$$
\begin{gathered}
F E V_{\omega}=\sum_{i=1}^{x} F E V_{i} \forall i \in \omega \\
\text { averageFE } V_{\omega}=\frac{\sum_{i=1}^{x} F E V_{i}}{\sum_{i=1}^{x} i} \text { where } i \in F E V>0 \wedge \forall i \in \omega \\
a F E V_{\omega}=F E V_{\omega} \cdot r \\
\text { average_aFE } V_{\omega}={\text { averageFE } V_{\omega} \times r}^{\text {averate }}
\end{gathered}
$$

where $\omega$ is $\omega$-th administrative level, $i$ is $\mathrm{i}$-th pixel in the map, the expression $i \in F E V>0 \wedge \forall i \in \omega$ represents forest surfaces with positive FEV for $\omega$-th administrative level, and $\mathrm{r}$ is interest rate.

In each scenario $s$, the amount of timber potentially obtained was calculated on the basis of forest surface with positive FEV, forest type and partitioning (percentage) of biomass increment in each wood assortment. The analysis of economic losses was focused on forest surfaces where FEV $>0$ in WO scenario because damage evaluation must compare ex-ante (WO scenario) and ex-post (POD1) situations. Therefore, in the hypothesis of timber products investigation, an economic damage exists if and only if forest area can be economically processed also in WO scenario. The main assortments considered as typical for Italy are roundwood, timber pole, paper mill and firewood ${ }^{19}$.

Long-term economic valuation (that is typical in forest sector) is very variable relative to the interest rate applied for capitalization. Therefore, a sensitivity analysis based on variation of the interest rate $r$ was performed at national level. In other terms, economic metrics (outputs, see Table 1) were computed for three different interest rates $(2 \%, 3 \%$ and $4 \%)$ that are appropriate in Italy on the basis of forest and forest owners' characteristics ${ }^{41}$. Sensitivity analysis facilitates depiction of potential range of results when input variables can cause high level of uncertainty in the outputs. Regional evaluation considered-for brevity-only $r=3 \%{ }^{43}$ for quantification of FEV as well as forest surface with positive FEV.

To link biomass from dose response functions to economic losses, the $\mathrm{O}_{3}$-induced biomass reductions (POD1 scenario) were attributed to the forest map by overlaying spatial locations. The forest map was created based on Corine Land Cover (CLC) polygons (Table S1). Each CLC forest polygon reports one forest category and was linked to one biogeographical region of Italy (i.e. alpine, continental or Mediterranean ${ }^{44}$ ). The CLC polygons were associated, through specific alphanumeric rules, to the forest types applied to compute dose-response functions (alpine deciduous, alpine evergreen, continental deciduous, continental evergreen, Mediterranean deciduous, Mediterranean evergreen). In case of lack of spatial matching among CLC polygons and POD1 forest types, a geographical extension of POD1 information was performed by means of proximity analysis (i.e. Voronoi tassellation of POD1 centroids ${ }^{45}$ ). The results were finally mapped by QGIS (https://www.qgis.org/it/site/).

Received: 19 September 2020; Accepted: 20 November 2020

Published online: 08 January 2021

\section{References}

1. Sicard, P. et al. Projected global tropospheric ozone impacts on vegetation under different emission and climate scenarios. Atmos. Chem. Phys. 17, 12177-12196 (2017).

2. Mills, G. et al. Tropospheric Ozone Assessment Report: Present-day tropospheric ozone distribution and trends relevant to vegetation. Elem. Sci. Anthr. 6, 47 (2018).

3. Paoletti, E. Ozone impacts on forests. CAB Rev. Persp. Agric. Vet. Sci. Nutr. Nat. Res. 2, 68 (2007).

4. Lefohn, A. S. et al. Tropospheric Ozone Assessment Report: Global ozone metrics for climate change, human health, and crop/ ecosystem research. Elem. Sci. Anthr. 6, 39 (2018). 
5. Paoletti, E. \& Manning, W. J. Toward a biologically significant and usable standard for ozone that will also protect plants. Environ. Pollut. 150, 85-95 (2007).

6. CLRTAP Mapping Critical Levels for Vegetation, Chapter III of manual on methodologies and criteria for modelling and mapping critical loads and levels and air pollution effects, risks and trends. UNECE Convention on Long-range Transboundary Air Pollution. http://icpvegetation.ceh.ac.uk/ (2017)

7. De Marco, A. et al. Impacts of air pollution on human and ecosystem health, and implications for the National Emission Ceilings Directive: insights from Italy. Environ. Int. 125, 320-333 (2019).

8. Emberson, L., Ashmore, M. R., Cambridge, H. M., Simpson, D. \& Tuovinen, J. P. Modelling stomatal ozone flux across Europe. Environ. Pollut. 109, 403-413 (2000).

9. Karlsson, P. E. et al. Economic assessment of the negative impacts of ozone on crop yields and forest production. A case study of the estate Östads Säteri in Southwestern Sweden. Ambio 34, 32-40 (2005).

10. Felzer, B. et al. Future effects of ozone on carbon sequestration and climate change policy using a global biogeochemical model. Clim. Change 73, 345-373 (2005).

11. Feng, Z. et al. Economic losses due to ozone impacts on human health, forest productivity and crop yield across China. Environ. Int. 131, 104966 (2019).

12. Gao, F. et al. Water stress mitigates the negative effects of ozone on photosynthesis and biomass in poplar plants. Environ. Pollut. 230, 268-279 (2017).

13. Hoshika, Y. et al. Ozone risk assessment in three oak species as affected by soil water availability. Environ. Sci. Pollut. Res. 25, 8125-8136 (2018).

14. Hoshika, Y., Paoletti, E. \& Omasa, K. Parameterization of Zelkova serrata stomatal conductance model to estimate stomatal ozone uptake in Japan. Atmos. Environ. 55, 271-278 (2012).

15. Robert, N., Jonsson, R., Chudy, R. \& Camia, A. The EU bioeconomy: Supporting an employment shift downstream in the woodbased value chains?. Sustainability (Switzerland) 12, 758 (2020).

16. Paoletti, E. Impact of ozone on Mediterranean forests: a review. Environ. Pollut. 144, 463-474 (2006)

17. Sicard, P. et al. Decrease in surface ozone concentrations at Mediterranean remote sites and increase in the cities. Atmos. Environ. 79, 705-715 (2013).

18. ISTAT. 8th Italian Census on Industries and Services. https://www.istat.it/it/censimenti-permanenti/censimenti-precedenti/indus tria-e-servizi/imprese-2001 (2001).

19. Sacchelli, S., Cipollaro, M. \& Fabbrizzi, S. A GIS-based model for multiscale forest insurance analysis: the Italian case study. For. Pol. Econ. 92, 106-118 (2018).

20. De Marco, A., Anav, A., Sicard, P., Feng, Z. \& Paoletti, E. High spatial resolution ozone risk assessment for Asian forests. Environ. Res. Lett. 15, 104095 (2020).

21. Paoletti, E. et al. Challenges, gaps and opportunities in investigating the interactions of ozone pollution and plant ecosystems. Sci. Total Environ. 709, 136188 (2020).

22. Sicard, P. et al. High spatial resolution WRF-Chem model over Asia: physics and chemistry evaluation. Atmos. Environ. 244, 118004 (2021).

23. Bičárová, S., Sitková, Z. \& Pavlendová, H. Ozone phytotoxicity in the western Carpathian mountains in Slovakia. For. J. 62, 77-88 (2016).

24 Karlsson, P. E. et al. Past, present and future concentrations of ground-level ozone and potential impacts on ecosystems and human health in northern Europe. Sci. Total Environ. 576, 22-35 (2017).

25. Li, P. et al. Nationwide ground-level ozone measurements in China suggest serious risks to forests. Environ. Pollut. 237, 803-813 (2018).

26. Anav, A. et al. Comparing concentration-based (AOT40) and stomatal uptake (PODy) metrics for ozone risk assessment to European forests. Glob. Change Biol. 22, 1608-1627 (2016).

27. Zvyagintsev, A. M., Kakadzhanova, G., Kruchenitskii, G. M. \& Tarasova, O. A. Periodic variability of surface ozone concentration over western and central Europe from observational data. Russ. Met. Hydrol. 33, 159-166 (2008).

28. Mills, G. et al. New stomatal flux-based critical levels for ozone effects on vegetation. Atmos. Environ. 45, 5064-5068 (2011).

29. Ferrara, C., Carlucci, M., Grigoriadis, E., Corona, P. \& Salvati, L. A comprehensive insight into the geography of forest cover in Italy: exploring the importance of socioeconomic local contexts. For. Policy Econ. 75, 12-22 (2017).

30. Vacchiano, G., Garbarino, M., Lingua, E. \& Motta, M. Forest dynamics and disturbance regimes in the Italian Apennines. For. Ecol. Manag. 388, 57-66 (2017).

31. Grilli, G., Fratini, R., Marone, E. \& Sacchelli, S. A spatial-based tool for the analysis of payments for forest ecosystem services related to hydrogeological protection. For. Policy Econ. 111, 102039 (2020).

32. Sarukhán, J. et al. Millenium Ecosystem Assessment: Ecosystem and Human Well-Being: Biodiversity Synthesis (Island Press, Washington, DC, 2005).

33. Costanza, R. et al. Changes in the global value of ecosystem services. Glob. Environ. Change 26, 152-158 (2014).

34. Agathokleous, E. et al. Ozone affects plant, insect and soil microbial communities: a threat to terrestrial ecosystems and biodiversity. Sci. Adv. 6, eabc176 (2020).

35. Busetto, L., Barredo Cano, J. \& San-Miguel-Ayanz, J. Developing a spatially-explicit pan-European dataset of forest biomass increment. In Proceedings of the 22nd European Biomass Conference and Exhibition, Hamburg 2014. European Biomass Conference; 2014. p. 41-46. JRC87643 (2014).

36. INFC. Inventario Nazionale delle Foreste e dei serbatoi di Carbonio [National Forest Inventory of Forest and Carbon Sink] https:// www.sian.it/inventarioforestale/jsp/obiettivi_intro.jsp?menu=3 (2017).

37. Büker, P. et al. New flux based dose-response relationships for ozone for European forest tree species. Environ. Pollut. 206, 163-174 (2015).

38. Anav, A. et al. The role of plant phenology in stomatal ozone flux modelling. Glob. Change Biol. 24, 235-248 (2018).

39. Sacchelli, S., Zambelli, P., Zatelli, P. \& Ciolli, M. Biomasfor: an open-source holistic model for the assessment of sustainable forest bioenergy. iForest 6, 285-293 (2013).

40. Manley, B. \& Bare, B. B. Equivalence of the expectation and cost compounding methods of forest valuation - Faustmann revisited. N. Z. J. For. Sci. 48(1), 25-31 (2003).

41. Merlo, M. Elementi di economia ed estimo forestale - ambientale, 55 (Pàtron Editore, Bologna, 1991).

42. Faustmann, M. On the determination of the value which forestland and immature stands pose for forestry. J. For. Econ. 1, 7-44 (1995).

43. Barreal, J., Loureiro, M. L. \& Picos, J. On insurance as a tool for securing forest restoration after wildfires. For. Policy Econ. 42, 15-23 (2014).

44. Cervellini, M. et al. A grid-based map for the Biogeographical Regions of Europe. Biodiv. Data J. 8, e53720 (2020).

45. Fortune, S. J. A sweepline algorithm for Voronoi diagrams. Algorithmica 2, 153-174 (1987). 


\section{Acknowledgements}

We greatly thank the LIFE project MOTTLES ("MOnitoring ozone injury for seTTing new critical LEvelS”, LIFE15 ENV/IT/000183) and the NEC Italia project coordinated by Carabinieri Forestali (CUFA) for economic support to this study.

\section{Author contributions}

E.P., E.C., A.D.M., S.S., P.S.: conceptualization and investigation, S.S., E.C., A.A., P.S., A.D.M., A.S., G.C., C.C.: data curation and analysis, E.P., S.S., A.D.M., P.S., Y.H., writing-original draft; All authors: writing-review \& editing.

\section{Competing interests}

The authors declare no competing interests.

\section{Additional information}

Supplementary information The online version contains supplementary material available at https://doi. org/10.1038/s41598-020-80516-6.

Correspondence and requests for materials should be addressed to E.P.

Reprints and permissions information is available at www.nature.com/reprints.

Publisher's note Springer Nature remains neutral with regard to jurisdictional claims in published maps and institutional affiliations.

(c) (i) Open Access This article is licensed under a Creative Commons Attribution 4.0 International License, which permits use, sharing, adaptation, distribution and reproduction in any medium or format, as long as you give appropriate credit to the original author(s) and the source, provide a link to the Creative Commons licence, and indicate if changes were made. The images or other third party material in this article are included in the article's Creative Commons licence, unless indicated otherwise in a credit line to the material. If material is not included in the article's Creative Commons licence and your intended use is not permitted by statutory regulation or exceeds the permitted use, you will need to obtain permission directly from the copyright holder. To view a copy of this licence, visit http://creativecommons.org/licenses/by/4.0/.

(C) The Author(s) 2021 